\title{
Um Ano de Química, o Ano Internacional da Química
}

\author{
JOAQUIM LUÍS FARIA*
}

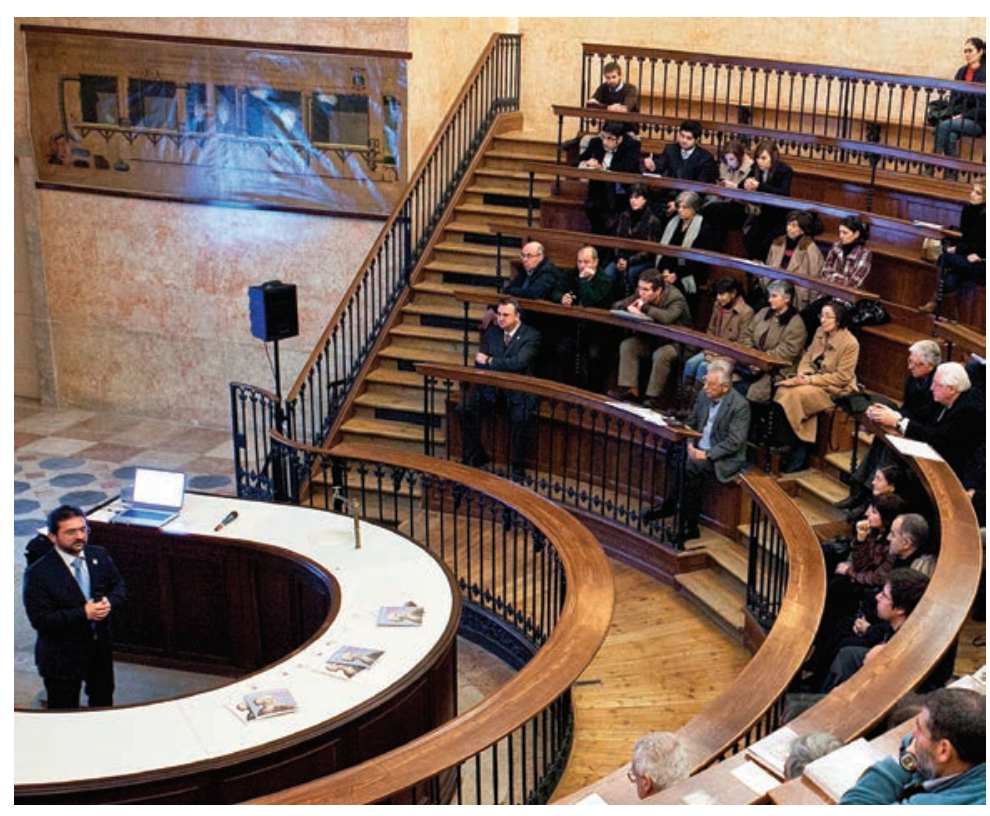

Foi no número 120 do QUÍMICA que lançamos o ANO INTERNACIONAL DA QUÍMICA (AIQ) em simultâneo com as comemorações dos 100 ANOS de SPQ, 1911-2011. Num apelo sincero pedia-se que, durante esse ano, cada sócio da SPQ, ainda mais que nos anos normais, fosse um divulgador convicto desta ciência junto dos seus amigos, familiares, colegas e conhecidos. Quando esse fascículo chegou às mãos dos nossos sócios, a máquina já estava em movimento e pela amostra contida nas (10) páginas do primeiro noticiário SPQ do AIQ percebia-se que o repto tinha sido plenamente aceite por todos.

E no espírito de celebrar nesse ano as contribuições das mulheres para a Química, o evento inicial foi protagonizado no feminino com o emblemático "Women Sharing a Chemical Moment in Time" - uma refeição global (era para ser um pequeno almoço) que teve lugar em 100 locais diferentes de 44 países espalhados pelo globo, ao longo de 24 fusos horários, iniciado em Wellington (Nova Zelândia) e terminado no Hawai. Estávamos a

\footnotetext{
* Secretário Geral da SPQ (jlfaria@fe.up.pt)
}

18 de janeiro de 2011, ainda antes do lançamento oficial do AIQ 2011 (que ocorreu a 27-28 de janeiro). Em Portugal, o encontro entre químicas teve lugar em várias universidades e honras de cobertura televisiva (um dos raros eventos dado a tal distinção!) com divulgação nos telejornais nacionais, incluindo a entrevista a uma das organizadoras, a Prof. Filomena Camões.

Ao longo de 2011 e princípio de 2012 , a SPQ registou mais de 500 eventos distintos, fruto do empenho de várias instituições, empresas e organizações que se associaram ao AIQ. A SPQ assumiu tão somente o papel de ponto focal nacional e funcionou enquanto dinamizadora, promotora e divulgadora das várias iniciativas que proliferavam por todo o país. Ciente das suas limitações e tendo em conta a conjuntura pouco favorável que se começava a desenhar nessa altura, a $S P Q$ definiu como seus objetivos para a concretização nacional de um AIQ participado, a mobilização dos químicos, dos professores e dos estudantes de Química. Entendeu-se que seria essencial estabelecer o diálogo entre os departamentos de Química, Bioquímica e Engenharia Química, bem como com os outros departamentos ou instituições onde a Química tivesse um papel relevante. Nesse sentido, foi criada, a 2 de dezembro de 2010, a Comissão Nacional para o Ano Internacional da Química/Centenário da SPQ, com a seguinte constituição:

- Jorge Calado - Presidente

- José Artur Martinho Simões - Vice-Presidente

- Mário Berberan e Santos

- Joaquim L. Faria

- João Paulo André

- Paulo Ribeiro Claro

- Margarida Bastos

- Maria João Ramos

- Carlos Nieto de Castro

- Paulo Mendes

- Cristina Galacho

- Sebastião Formosinho

- João Manuel Rodrigues

- Joaquim Marçalo

- Maria Paula Robalo

- Rosa Rego

- M. Isabel da Costa Ismael

- Rui Sant'Ovaia

- Ana Noronha

O papel desta Comissão Nacional era o de elaborar um programa único a nível nacional, capaz de aproveitar ao máximo os esforços dos vários grupos envolvidos e criar sinergias entre eles, coordenando e consolidando ações de diferentes áreas geográficas ou mesmo de diferente natureza. Pretendia-se garantir assim a realização de um leque de eventos adaptado a várias situações e públicos. A SPQ comprometia-se a usar os meios ao seu alcance para proporcionar a devida divulgação, de maneira a chegar ao maior número possível de pessoas, tentando desmistificar algumas ideias pré-concebidas sobre a Química, procurando entusiasmar os jovens e estimular a sua criatividade científica, ao mesmo tempo que procurava criar 
no público em geral a consciência de que, pela sua natureza e predominância no mundo que nos rodeia, a Química é mesmo a ciência central.

Além do seu papel de promotora, a SPQ assumiu ainda a responsabilidade de apoiar parcial, ou totalmente, certos eventos que não conseguiam apoio de outra forma e que pela sua natureza justificavam uma atenção particular. Para tal foi necessário reforçar e adequar os meios humanos existentes e procurar o apoio financeiro que se tornou, à medida que o ano avançava, cada vez mais parcamente disponível, sobretudo devido ao clima de degradação económica que se vivia particularmente em Portugal (e no resto da Europa em geral). Foi por isso importante o contributo dos departamentos e instituições ligados à química, do poder local a vários níveis, dos institutos de turismo, da indústria química através de algumas das suas maiores empresas nacionais e de empresas multinacionais instaladas em Portugal, bem como de empresas de equipamentos, editoras nacionais, grupos financeiros e outras empresas sem ligação direta à química, mas com grandes responsabilidades na economia nacional. Seria injusto proceder à nomeação de todas elas aqui, mas constarão de um relatório exaustivo que será tornado público muito em breve, para que se possa apreciar a devida dimensão da conjugação de esforços levada a cabo.

De forma a aumentar a visibilidade e ajudar à penetração junto das camadas mais jovens, foi criado um portal dedicado ao AIQ 2011 (www.spq.pt/ quimica2011) e um mural no facebook, que eram atualizados diariamente.

Paralelamente, tentou-se de forma continuada, mesmo insistente, a mobilização dos meios de comunicação social, tendo-se conseguido entrevistas na TVI e na agência LUSA, do presidente da Comissão Nacional, Prof. Jorge Calado. Uma participação alargada no programa Sociedade $\mathrm{Ci}$ vil (RTP) por parte do presidente da SPQ, o Prof. Mário Nuno Berberan e Santos. Cobertura televisiva da Noite da Química no IST (SIC). Participação no programa radiofónico "Semana da Química” (Rádio Renascença). Publi-

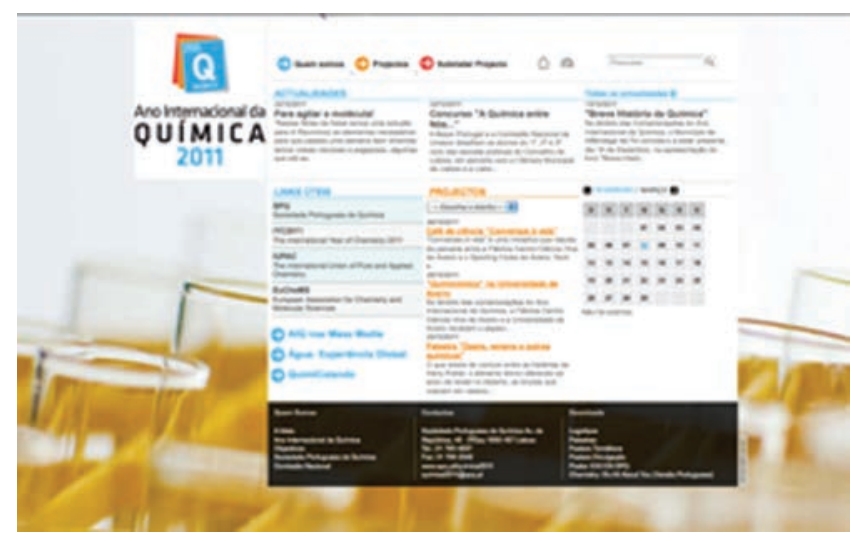

Página de entrada do portal dedicado ao AIQ 2011

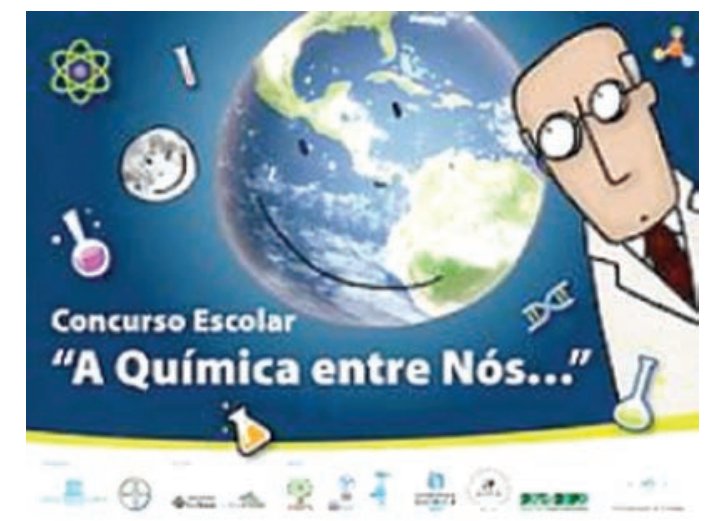

Cartaz de divulgação do concurso escolar "A Química entre Nós..."

cação da peça jornalística "Um Dia na Vida de um Químico", no jornal Público. Apesar de tudo, estes apontamentos complementados com outros pontuais em jornais de índole regional e escolar, atestam a dificuldade de se fazer passar a mensagem química através dos grandes meios de comunicação.

Foram produzidos vários elementos de merchandising no âmbito do $\mathrm{AIQ}$ e dos 100 ANOS SPQ, que incluíram posters publicitários, alfinetes, uma edição especial de um bilhete postal pelos CTT, sacos, fitas e autocolantes. No caso dos autocolantes, é de mencionar que se tratou de um trabaIho artístico criado sobre os slogans concebidos por jovens no âmbito de um concurso nacional que correu escolas de todo o país. No fim foi necessário escolher 3 de entre cerca de 400 frases submetidas a concurso.

Um outro exemplo de concurso foi levado a cabo pela Bayer Portugal e pela Comissão Nacional da Unesco (em parceria com a Câmara Municipal de Lisboa e a Lisboa E-nova), que desafiaram os alunos do $1 .^{\circ}, 2 .^{\circ}$ e $3 .^{\circ} \mathrm{Ci}$ clos das escolas públicas do ConceIho de Lisboa a concluir de uma forma original, através de texto ou de artes plásticas, o último capítulo dos livros de Maria Helena Henriques e de Maria José Moreno, "Terra Vita Sadia".

No caso das ações para o grande público, são de referir as "Noites da Química" que ocorreram em Faro, Lisboa, Évora, Coimbra, Porto, Aveiro, Braga e Bragança. Nalguns casos, estas ações decorreram associadas à "Noite dos Investigadores" e foi uma forma de permitir o contacto direto entre cientistas e jovens, bem como permitir aos mais novos participar em várias experiências de bancada sob a supervisão de investigadores: os miúdos (e alguns graúdos) puderam produzir e provar deliciosos gelados, fabricar bolas saltitonas e interrogar a seu bel-prazer investigadores sobre os seus projetos em curso, ou simplesmente sobre temas químicos em sessões de speed-dating.

A SPQ foi ainda convidada a participar na produção do Pavilhão da Ciência da Festa do Avante, proporcionando uma viagem química aos milhares de visitantes que aí se deslocaram. A SPQ contribuiu ainda para o programa de palestras sobre a química que 


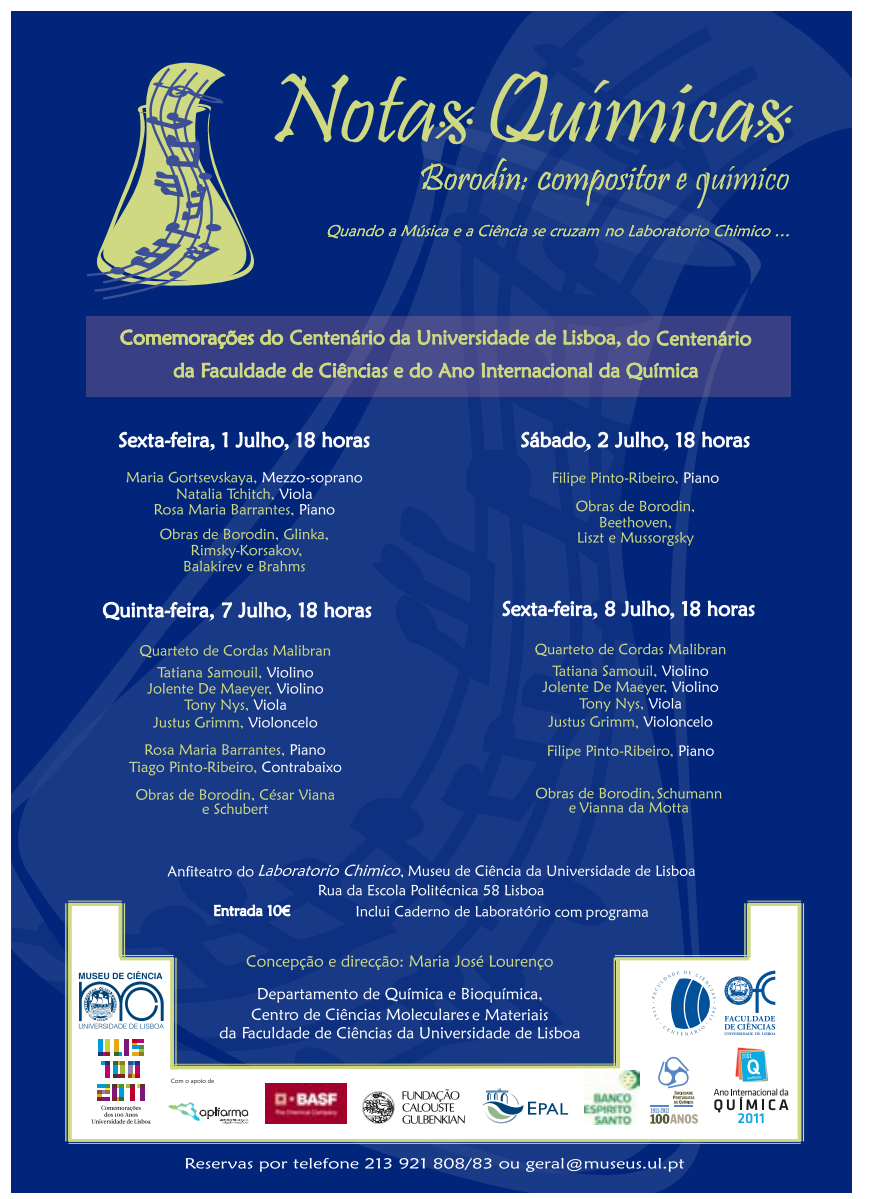

Cartaz de divulgação da iniciativa "Notas Químicas - Borodin Compositor e Químico"

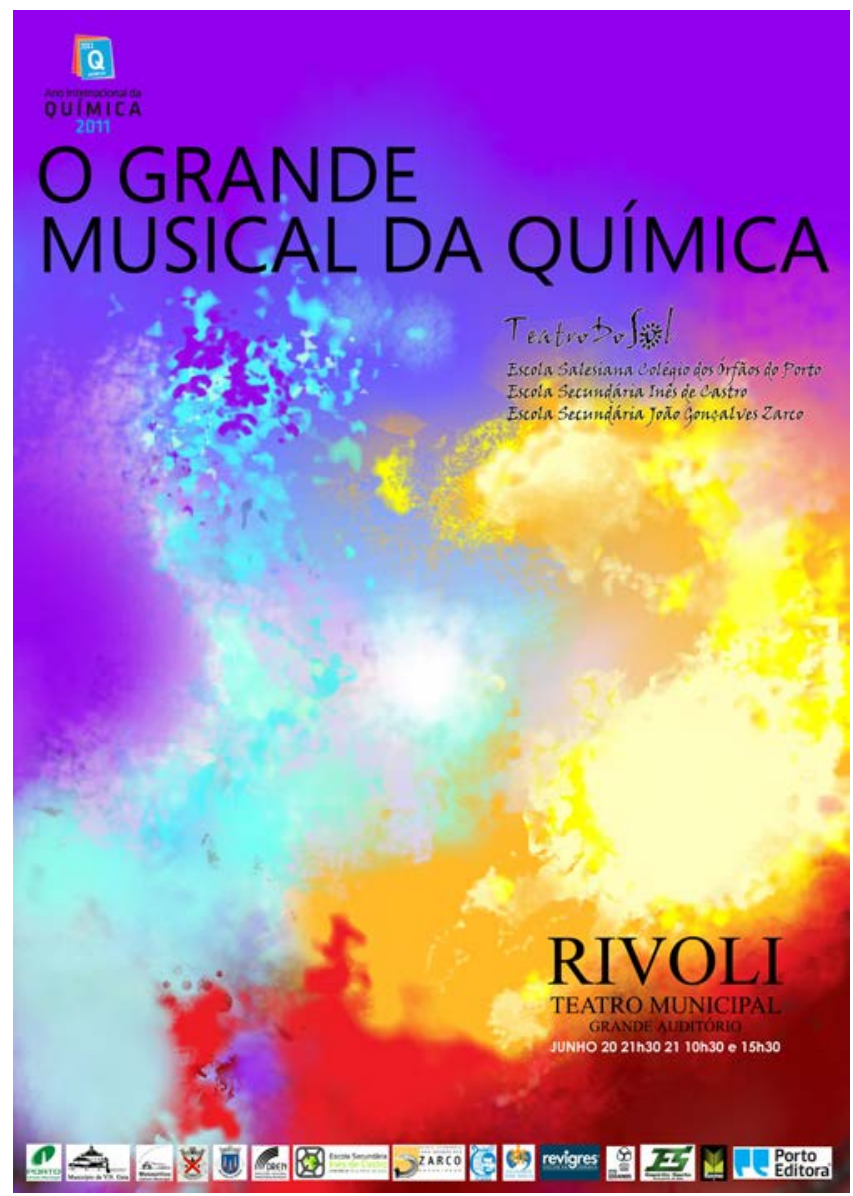

Cartaz de divulgação da peça de teatro "O Grande Musical da Química" teve lugar durante o festival e esteve envolvida na realização de uma exposição itinerante sobre a química que após a sua inauguração nessa festa, correu já várias escolas do país. Várias outras exposições e mostras documentais foram apresentadas por todo o país.

No campo das expressões artísticas foi levada à cena a peça "Falácia" de Carl Djerassi (tradução de Manuel João Monte), pela Seiva Trupe do Teatro do Campo Alegre, com direção de Júlio Cardoso, que teve a particularidade da estreia portuguesa ter tido lugar na data de aniversário do autor, que estando presente recebeu do público uma enorme salva de parabéns. A música também esteve presente na iniciativa "Notas Químicas - Borodin Compositor e Químico", patrocinada pela SPQ - um conjunto de concertos concebidos para mostrar ao público como música e ciência se podem cruzar de forma compatível e harmoniosa. O evento foi da responsabilidade do Departamento de Química e Bioquímica da Faculdade de Ciências da Universidade de Lisboa (FCUL) e do Museu de Ciência da Universidade de Lisboa.

Num registo distinto, mais virado para um público infanto-juvenil, estreou a 20 de Junho, no Teatro Rivoli do Porto, "O Grande Musical da Química", baseado no livro "Breve História da Química" da professora Regina Gouveia, publicação coeditada pela SPQ (ver artigo no QUÍMICA 122).

A SPQ foi ainda coeditora do livro "A História Química de uma Vela”, de Michael Faraday (Imprensa da Universidade de Coimbra), tradução de Maria Isabel Prata e Sérgio Rodrigues, cuja edição em português serviu de pretexto para a recriação das experiências aí contidas, nos Museus da Ciência de Lisboa e de Coimbra, pelo próprio Dr. Sérgio Rodrigues, assistido pela Dra Filipa Oliveira, e ainda na Faculdade de Ciências da UP.

No centenário da sua fundação, e também associado ao AIQ, foi editada pela SPQ, uma cuidada tradução (Emídio C. Queiroz Lopes) do "Tratado Elementar de Química", de Antoine-Laurent Lavoisier, com o apoio das empresas Solvay e Hovione. O 